\title{
Pengaruh Diameter Knalpot Sepeda Motor Terhadap Intensitas Bunyi
}

\author{
Parmin Lumban Toruan ${ }^{1 *}$ \\ ${ }^{1 *}$ Program Studi Fisika, FMIPA Universitas PGRI Palembang \\ Palembang 30251, Indonesia \\ *e-mail : parmin.lt70@gmail.com
}

\begin{abstract}
Abstrak
Bising merupakan hasil sampingan dari suara kendaraan yang sering melintas dan tidak dapat kita hindari dari kehidupan sehari-hari. Penelitian ini bertujuan untuk mengetahui nilai intensitas bunyi yang ditimbulkan oleh kenderaan dengan diameter knalpot yang berbeda serta membandingkannya dengan intensitas bunyi yang di peroleh atau kebisingan dengan ambang baku tingkat kebisingan berdasarkan KMLH Kep-48/MENLH/1996. Metode yang digunakan adalah metode eksperimen yaitu pengambilan data kebisingan dengan menggunakan alat sound level meter. Hasil penelitian diketahui bahwa diameter knalpot sepeda motor mempunyai pengaruh terhadap intensitas bunyi yaitu semakin besar diameter knalpot sepeda motor maka intensitas bunyi yang dihasilkan semakin besar. Pada saat gas tinggi( $15000 \mathrm{rpm}) \mathrm{Knalpot}$ berdiameter $10 \mathrm{~mm}$ menghasilkan intensitas bunyi sebesar $10^{-3,497} \mathrm{w} / \mathrm{m}^{2}$ dan motor tanpa knalpot menghasilkan intensitas bunyi sebesar $10^{-1,987} \mathrm{w} / \mathrm{m}^{2}$, sedangkan pada gas normal (7000rpm) nilai intensitas bunyi pada diameter $10 \mathrm{~mm}$ sebesar $10^{-5,472} \mathrm{w} / \mathrm{m}^{2}$ dan motor tanpa knalpot intensitas bunyi sebesar $10^{-2,595} \mathrm{w} / \mathrm{m}^{2}$.
\end{abstract}

Kata Kunci: Bising, Intensitas Bunyi, Knalpot Motor

\section{Effect of Motorcycle Exhaust Diameter on Sound Intensity}

\section{Abstract}

Noise is a by-product of the sound of vehicles that often pass and we cannot avoid from everyday life. This study aims to determine the value of the sound intensity caused by vehicles with different exhaust diameters and to compare it with the intensity of sound obtained or noise with a standard threshold of noise level based on KMLH Kep-48 / MENLH / 1996. The method used is an experimental method that is collecting noise data using a sound level meter. The results of the study are known that the diameter of the motorcycle's knuckle has an influence on the sound intensity ie the greater the diameter of the motorcycle's exhaust, the greater the intensity of the sound produced. When gas is high (15000 rpm) Muffler with a diameter of $10 \mathrm{~mm}$ produces sound intensity of 10-3,497 w/ m2 and a motor without exhaust produces sound intensity of 10-1,987 w/ m2, whereas in normal gas (7000rpm) the value of sound intensity at a diameter of $10 \mathrm{~mm}$ amounted to $10-5,472 \mathrm{w} / \mathrm{m} 2$ and the motor without exhaust sound intensity was 10-2,595 w/ $\mathrm{m} 2$.

Keywords: Noise, Sound Intensity, motorcycle exhaust

\section{PENDAHULUAN}

Aktivitas serta Pertumbuhan penduduk yang semakin pesat mendorong meningkatnya penggunaan sarana transportasi baik darat, udara maupun laut. Hal ini mengakibatkan setiap orang akan berlomba (berkompetisi) untuk mencapai tempat yang akan dituju lebih cepat sampai, sehingga dibutuhkan transportasi. Jumlah kendaraan di Indonesia pada setiap tahun terus meningkat. Pada tahun 2019 jumlah kendaraan penggunaan kendaraan roda dua meningkat pesat dari 104,211 juta unit kendaraan pada tahun 2018 meningkat menjadi 143,75 juta unit kendaraan pada tahun 2019 (BPS, 2019). Kendaraan roda dua atau motor menjadi pilihan favorit masyarakat. Motor dipilih karena harganya yang bisa dijangkau 


\section{Pengaruh Diameter Knalpot... Jupiter... Vol 1 No 2...Februari 2020...19-24 \\ Parmin Lumbantoruan}

oleh hampir semua kalangan masyarakat (Amin, 2017).

Keadaan tempat tinggal dikawasan perkotaan maupun desa yang semakin berkembang saat ini terasa tidak nyaman atau terasa bising yang ditimbulkan oleh bunyi suara kendaraan seperti mobil, motor, pesawat, dan kereta api yang sering melintas. Hal ini tidak menutup kemungkinan dapat mengganggu Kesehatan dan kenyamanan masyarakat. Kebisingan merupakan suatu permasalahan yang cukup penting terutama dalam kaitannya dengan kenyamanan. Tingkat kebisingan yang berlebihan dapat memberikan dampak negatif yang sangat berbahaya dalam banyak hal, yaitu dampak dari segi kesehatan dan juga dari segipsikologis serta teknis (wibowo, 2014). Knalpot merupakan alat peredam kebisingan pada kendaraan (Pasaribu, 2016). Knalpot dirancang sedemikian rupa agar suara yang keluar tidak begitu keras dan mampu menyerap bising yang dihasilkan oleh kendaraan.

Knalpot adalah suatu komponen pada kendaraan yang berfungsi sebagai peredam hasil ledakan di ruang bakar.Ledakan ini menimbulkan suara yang sangat bising. Untuk meredam suara gas sisa hasil pembakaran yang keluar dari klep buang tidak langsung dilepas ke udara terbuka. Gas buang disalurkan terlebih dahulu ke dalam peredam suara atau muffler di dalam knalpo (Seprihadaniansyah, 2018).

Para modifikator Knalpot sering kali memanfaatkan sisa pembakaran untuk meningkatkan perfoma atau kecepatan kendaraan. Modisikasi alat pembuangan hasil pembakaran yang diubah, tentu akan berdampak pada sisi yang lain yaitu kebisingan. Berdasarkan Peraturan Menteri (Permen) Lingkungan Hidup No. 07 Tahun 2009 disebutkan batasan tingkat kebisingan suara knalpot (dB) untuk mobil maupun motor. Yakni, untuk motor di bawah $80 \mathrm{cc}$, batasan kebisingannya dipatok 80 desibel $(\mathrm{dB})$.
Sedang motor di atas 80-175 cc tak boleh lebih dari 90 desibel (dB). Motor di atas 175 cc maksimal 90 dB. Ketentuan tingkat kebisingan motor Indonesia ini mengacu standar global ECE (Economic Comission for Europe)-R-41-01.

Ukuran diameter knalpot standar yang dikeluarkan pabrik merupakan diameter knalpot yang sudah melalui uji sehingga tidak menimbulkan bunyi atau suara yang bising.

Penelitian ini dilakukan untuk mengetahui sejauh mana pengaruh ukuran diameter knalpot terhadap intensitas bunyi yang dihasilkan sehingga dapat mempengaruhi kenyamanan lingkungan.

\section{BAHAN DAN METODE}

Penelitian ini dilakukan di Laboratorium Fisika Universitas PGRI Palembang pada bulan Januari 2020.

Alat yang digunakan pada penelitian ini adalah: Sound Level Meter dengan Interval deteksi 35-130 dB, Rool Meter Knalpot motor dengan berbagai ukuran diameter, Sepeda motor vespa. Jangka sorong.

Metode penelitian yang digunakan adalah metode eksperimen yaitu pengambilan data secara langsung dari lapangan.

Prosedur penelitian ditunjukkan pada bagan alir dibawah ini:

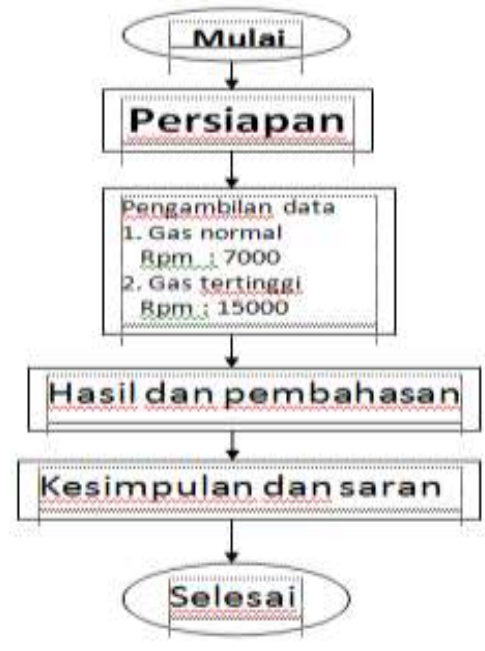




\section{HASIL DAN PEMBAHASAN}

Hasil Penelitian diberikan pada tabel 1 di bawah ini.

Tabel 1. Taraf Intensitas Bunyi Pada Gas Normal

\begin{tabular}{cccccccc}
\hline Diameter & \multicolumn{6}{c}{ Taraf Intensitas (dB) } & \multirow{2}{*}{ Rata-rata TI } \\
\cline { 2 - 6 } Knalpot & 1 & 2 & 3 & 4 & 5 & 6 & \\
\cline { 2 - 6 } $10 \mathrm{~mm}$ & 64,5 & 64,8 & 66,8 & 66,5 & 65,3 & 63,8 & $65,28 \pm 0,194$ \\
$20 \mathrm{~mm}$ & 74,1 & 75,8 & 75,9 & 74,8 & 76,2 & 75,7 & $75,25 \pm 0,130$ \\
$30 \mathrm{~mm}$ & 78,2 & 78,4 & 77,8 & 78,1 & 77,7 & 77,5 & $77,95 \pm 0,054$ \\
Tanpa Knalpot & 93,8 & 94,3 & 93,5 & 93,9 & 94,6 & 94,2 & $94,05 \pm 0,065$ \\
\hline
\end{tabular}

Pada tabel 1 diatas ini terlihat bahwa taraf intensitas yang dihasilkan motor dalam penelitian menunjukkan peningkatan sebesar 65,28 dB, sedangkan pada motor tanpa knalpot sebesar 94,05 dB

Tabel 2. Taraf Intensitas Bunyi Pada Gas Tertinggi

\begin{tabular}{llllllll}
\hline \multirow{2}{*}{$\begin{array}{l}\text { Diameter } \\
\text { Knalpot }\end{array}$} & \multicolumn{7}{c}{ Taraf Intensitas (dB) } \\
\cline { 2 - 7 } 10 mm & 85,1 & 85,3 & 84,8 & 84,9 & 85,4 & 85,0 & $85,08 \pm 0,036$ \\
$20 \mathrm{~mm}$ & 87,5 & 88,0 & 87,7 & 87,3 & 88,3 & 88,1 & $87,81 \pm 0,063$ \\
$30 \mathrm{~mm}$ & 92,3 & 92,6 & 91,9 & 93,4 & 92,7 & 93,6 & $92,75 \pm 0,108$ \\
Tanpa knalpot & 100,5 & 100,2 & 99,7 & 99,9 & 100,1 & 100,5 & $100,13 \pm 0,051$ \\
\hline
\end{tabular}

Berdasarkan Tabel 2 diatas terlihat bahwa taraf intensitas yang dihasilkan motor dalam penelitian menunjukkan peningkatan yaitu pada knalpot yang berdiameter $10 \mathrm{~mm}$
85,08 dB, sedangkan pada motor tanpa knalpot sebesar 100,13 dB.

Tabel 3. Intensitas Bunyi berdasarkan diameter knalpot sepeda motor

\begin{tabular}{cccc}
\hline \multirow{2}{*}{$\begin{array}{c}\text { Merek } \\
\text { motor }\end{array}$} & Diameter & \multicolumn{2}{c}{ Intensitas Bunyi $\left(\boldsymbol{w} / \boldsymbol{m}^{2}\right)$} \\
\cline { 3 - 4 } & & Gas Normal & Gas Tinggi \\
\hline \multirow{3}{*}{ Vespa } & $10 \mathrm{~mm}$ & $10^{-5,472}$ & $10^{-3,497}$ \\
& $20 \mathrm{~mm}$ & $10^{-4,475}$ & $10^{-3,219}$ \\
& $30 \mathrm{~mm}$ & $10^{-4,205}$ & $10^{-2,725}$ \\
& Tanpa Knalpot & $10^{-2,595}$ & $10^{-1,987}$ \\
\hline
\end{tabular}

\section{PEMBAHASAN}

Dalam penelitian ini alat yang digunakan untuk mendeteksi bunyi adalah sound level meter yang interval deteksinya sebesar 35-130 dB. Pada sound level meter range yang digunakan sebesar 50-130 dB, kemudian diarahkan 
sejajar dengan motor pada saat pengambilan data. Dari sound level meter didapatkan taraf intensitas bunyi dengan satuan desibel (dB). Data yang di dapat dikelompokkan sesuai tara intensitas yang dihasilkan dengan menggunakan rumus

$$
T I=10 \log \frac{I}{I_{0}} . \ldots \ldots \ldots \ldots \ldots \ldots
$$

Dimana:

$\mathrm{TI}=$ Taraf Intensitas Bunyi $(\mathrm{dB})$

$\mathrm{I}=$ Intensitas Bunyi $(\mathrm{dB}$

$\mathrm{I}_{\mathrm{o}}=$ Intensitas Ambang Bunyi $(\mathrm{dB})$

Penelitian ini dilakukan pada gas normal dan gas tertinggi, berdasarkan hasil penelitian pada gas normal maka nilai intensitas bunyi terendah yang dihasilkan sebesar $10^{-5,472} \mathrm{w} / \mathrm{m}^{2}$ dan nilai tertingginya sebesar $10^{-2,595} \mathrm{w} / \mathrm{m}^{2}$, sedangkan pada gas tertinggi nilai intensitas bunyi terendah yang dihasilkan sebesar $10^{-3,497} \quad w / m^{2}$ dan nilai tertingginya sebesar $10^{-1,987} \mathrm{w} / \mathrm{m}^{2}$. Kemudian berdasarkan diameter maka dapat di lihat bahwa nilai intensitas bunyi terendah dihasilkan oleh diameter $10 \mathrm{~mm}$ dan nilai intensitas yang besar dihasilkan oleh diameter $30 \mathrm{~mm}$. pada motor tanpa knalpot intensitas bunyi yang dihasilkan sangat besar karena tidak adanya knalpot sebagai penyaring suara.

Penggunaan knalpot yang tidak standar akan mengakibatkan tingkat kebisingan semakin besar (Fadilah, 2016). Semakin besar diameter knalpot maka semakin besar intensitas bunyi yang dihasilkan karena pada knalpot yang diameter besar peredam tidak begitu banyak dibandingkan dengan diameter knalpot yang ukurannya standar pabrik. Sedangkan intensitas bunyi motor tanpa knalpot nilainya besar hal ini disebabkan tidak adanya knalpot sebagai peredam suara atau bunyi. Meningkatnya kecepatan aliran gas buang (gas semakin meninggi) dalam hal ini kecepatan putaran mesin bertambah mengakibatkan intensitas bunyi semakin besar (Suandika, 2009). Dalam penelitian ini pada gas normal motor putaran mesin sebesar 7000 rpm, sedangkan pada gas tinggi putaran mesin motor sebesar $15000 \mathrm{rpm}$. Alat yang digunakan untuk mengukur putaran mesin adalah tachometer yang berada pada dashboard. Penelitian ini dilakukan di luar ruangan guna menghindari terjadinya gaung, gema, dan pemantulan suara yang dapat menggangu bunyi yang diinginkan sebagaimana mestinya, walaupun tidak menutup kemungkinan data yang diambil dipengaruhi oleh kondisi lingkungan seperti suhu, kelembaban udara dan akibat resonansi pada bahan yang dipakai. Bunyi yang terhalang oleh bidang pembatas, maka besar kemungkinan bunyi tersebut akan dipantulkan kembali (Kho, 2014). Waktu penelitian dan pengambilan data dilakukan pada puku 120.00 WIB, karena pada saat itu kendaraan yang melintas sangat jarang. Intensitas bunyi pada siang hari lebih besar dibandingkan pada saat malam hari akibat jumlah kendaraan atau aktivitas meningkat (Jumingin, 2017)

Dari hasil penelitian dapat dilihat pengaruh diameter terhadap intensitas bunyi yang dihasilkan oleh sepeda motor yaitu semakin besar diameter knalpot maka semakin besar intensitas bunyi yang dihasilkan.

Dari nilai standar deviasi baku atau penyimpangan pada saat penelitian pada gas normal maka dapat terlihat bahwa standar deviasi baku pada motor berdiameter $10 \mathrm{~mm}$ yaitu sebesar 0,471 , ini biasa terjadi karena pada saat penelitian dipengaruhi keadaan lingkungan yaitu bunyi yang kita inginkan dapat bertambah akibat adanya sumber bunyi yang lain, sehingga intensitas bunyinya bertambah dan juga dapat dipengaruhi oleh kesalahan penelit yaitu pada pengambilan data dilakukan sebanyak 6 kali dan setiap kali pengambilan data gas yang ditarik tidak 


\section{Pengaruh Diameter Knalpot... Jupiter... Vol 1 No 2...Februari 2020...19-24 \\ Parmin Lumbantoruan}

selalu sama besarnya sehingga dapat mempengaruhi nilai sebenarnya. Standar deviasi baku pada motor berdiameter 10 mm sebesar $47,1 \%$. Sedangkan pada gas tinggi nilai standar deviasi baku atau penyimpangan pada saat penelitian terjadi pada motor tanpa knalpot yaitu sebesar 0,126 dan nilai ini juga dipengaruhi oleh keadaan lingkungan seperti : angin, kelembaban, material pipa yang digunakan, dan juga dipengaruhi keadaan sekitar seperti pada saat pengambilan data ada motor atau sumber bunyi yang lain lewat maka nilai yang kita dapatkan bertambah sehingga mempengaruhi nilai sebenarnya. Sedangkan nilai terbaik dan sesaatnya diambil dari perhitungan standar eror yang tertera pada lampiran. Di sini ada indikasi kesalahan pada saat penelitian yaitu pada gas normal yang terjadi pada knalpot motor berdiameter $10 \mathrm{~mm}$ sebesar 0,194, sedangkan pada gas tinggi kesalahan pada saat penelitian terjadi pada motor yang berdiameter $30 \mathrm{~mm}$ yaitu sebesar 0,108, ini dapat terjadi akibat pengaruh alat yang digunakan dan juga peneliti pada waktu pengambilan data sehingga nilai standar erornya sebesar 19,4 \% mendekati standar eror alat yang digunakan yaitu sebesar $20 \%$.

\section{KESIMPULAN}

Dari hasil penelitian yang telah dilakukan dapat ditarik kesimpulan sebagai berikut: semakin besar diameter knalpot maka semakin besar intensitas bunyi yang dikeluarkan mesin motor sehingga dapat menimbulkan kebisingan lingkungan dan berdasarkan penggunaan knalpot bahwa tanpa knalpot intensitas bunyi semakin besar.

\section{Ucapan Terima Kasih}

Saya mengucapkan terimakasih kepada ketua program studi Fisika Universitas PGRI Palembang atas motivasi dan semangat yang diberikan sehingga penelitian dan makalah ini dapat terselesaikan dengan baik.

\section{DAFTAR PUSTAKA}

Amin, M. C, (2017) Faktor- Faktor Yang Mempengaruhi Pertumbuhan Kendaraan Bermotor Roda Dua Di Kota Pekanbaru, Jurnal JOM Fekon 4(1) 1106-1119

Badan Pusat Statistik, (2020) Perkembangan Jumlah Kendaraan Bermotor Menurut Jenis tahun 2019 https://www.bps.go.id/linkTable Dinamis/view/id/1133

Fadilah, R.A. (2016) (Analisis Penggunaan Knalpot Model Free Flow dan Busi Racing Terhadap Torsi, Daya dan Tingkat Kebisingan Sepeda Motor 4 Langkah, (Skripsi), digilib.uns.ac.id

Jumingin, (2017), Taraf Intensitas Bunyi Kendaraan Bermotor Di Jalan Raya Pada Aktivitas Pengukuran Siang Hari, Jurnal Sainmatika, 14(2), 112-117

Kementerian Lingkungan Hidup, (2009)

Tentang Ambang Batas

Kebisingan Kendaraan Bermotor Tipe Baru, (PerMen LH No. 07)

Kementerian Lingkungan Hidup KMLH,(1996) Tentang Baku Tingkat Kebisingan, Kep48/MENLH/1996

Kho, W. K. (2014), Studi Material Bangunan Yang Berpengaruh Pada Akustik Interior. Jurnal Dimensi Interior, 12(2), 57-64

Pasaribu. M. H, (2016), Kebisingan Knalpot Standart Satria Fu 150 Dengan Knalpot Komposit Serat Batang Kelapa Sawit Berdasarkan Pada Kecepatan, repository.uhn.ac.id/handle/123 456789/874

Suandika. M, (2009), Studi Awal Emisi Kebisingan Knalpot Dengan Profil Silinder Yang Dibuat Dari Material Titanium Dengan 
Pengaruh Diameter Knalpot... Jupiter... Vol 1 No 2...Februari 2020...19-24

Parmin Lumbantoruan

menggunakan Simulasi Metode

Elemen Hingga), (Tugas

Sarjana, Universitas Summatera

Utara)

Seprihadaniansyah, G.M., Kuwoyo,A., Adrian,M. (2018) Modifikasi Knalpot Menggunakan Katalitik Konverter Dan Arang Akasia Guna Mengurangi Emisi Gas Buang Kendaraan. Jurnal Elemen 5(1), 11-19

Wibowo, M., Samuel, Budiarto.S.(2014) Analisa tingkat kebisingan kamar mesin pada kapal kmp. Jurnal Teknik Perkapalan, 2 (4) 